\title{
Characterization of key bio-nano interactions between organosilica nanoparticles and Candida albicans
}

Vidhishri Kesarwani ${ }^{1,3}$, Hannah G. Kelly², Madhu Shankar ${ }^{3}$, Kye J. Robinson ${ }^{1}$, Stephen J. Kent ${ }^{2}$, Ana Traven ${ }^{3 *}$ and Simon R. Corrie ${ }^{1 *}$

${ }^{1}$ Department of Chemical Engineering, Monash University, Clayton, Victoria, 3800, ARC Centre of Excellence in Convergent Bio-Nano Science and Technology

${ }^{2}$ Department of Microbiology and Immunology, Peter Doherty Institute for Infection and Immunity, The University of Melbourne, Melbourne, Victoria 3010, ARC Centre of Excellence in Convergent Bio-Nano Science and Technology

3 Infection and Immunity Program and the Department of Biochemistry and Molecular Biology, Biomedicine Discovery Institute, Monash University, Clayton, Victoria, 3800

Corresponding authors:

*Emails: simon.corrie@monash.edu; ana.traven@monash.edu 


\section{Table of Contents}

Viability of $C$. albicans yeast cells incubated with 800NP PEG

XPS Characterisation of uncoated, PEGylated and caspofungin-conjugated nanoparticles

Supplementary Figures

Figure S1: Nanoparticle size distribution

Figure S2: Viability of $C$. albicans yeast cells incubated with 800NP PEG.

Figure S3: Gating strategy of nanoparticle-cell association data. S-6

Table S1: XPS analysis of uncoated, PEGylated and caspofungin-conjugated nanoparticles S-6

Figure S4: Agar plate experiment with lower nanoparticle concentrations S-7

Figure S5: SEM image of untreated $C$. albicans yeast cells S-7

References S-8

\section{Supplementary Experimental Section}

\section{Viability of $C$. albicans yeast cells incubated with 800NP PEG}

Overnight cultures of $C$. albicans (SC5314) were diluted to OD of 0.2 in $1 \mathrm{~mL}$ of YPD containing nanoparticles $\left(5.49 \times 10^{9}\right.$ and $5.49 \times 10^{8} \mathrm{NP} \mathrm{mL}^{-1}$ of $\left.800 \mathrm{NP} \mathrm{PEG}\right)$ or in the absence of nanoparticles. Cells subjected to heat shock (by placing vials on the heat block set at $95^{\circ} \mathrm{C}$ ) for 10 minutes were taken as positive control and untreated cells were taken as negative control. Cells were incubated with nanoparticles for four hours at $30{ }^{\circ} \mathrm{C}$ with orbital shaking set to $200 \mathrm{rpm}$. Propidium iodide (2.5 $\mu \mathrm{L}$ of $1 \mathrm{mg} \mathrm{mL}^{-1}$, Thermofisher) was added to all cultures, washed with PBS and loaded on a 24-well plate where they were imaged using EVOS FL Auto Imaging System at a magnification of 40x.

\section{XPS Characterisation of uncoated, PEGylated and caspofungin-conjugated nanoparticles}

XPS analysis was performed on samples using an AXIS Nova spectrometer (Kratos Analytical Inc., Manchester, UK) with a monochromated Al K $\alpha$ source at a power of $180 \mathrm{~W}(15 \mathrm{kV} \times 12 \mathrm{~mA})$, a hemispherical analyser operating in the fixed analyser transmission mode and the standard aperture (analysis area: $0.3 \mathrm{~mm} \times 0.7 \mathrm{~mm}$ ). The total pressure in the main vacuum chamber during analysis was typically maintained between $10^{-9}$ and $10^{-8}$ mbar. Survey spectra were obtained at a pass energy of $160 \mathrm{eV}$. High resolution spectra were recorded from individual peaks at $40 \mathrm{eV}$ pass energy (yielding a typical peak width for polymers of $<1.0 \mathrm{eV}$ ) to obtain in-depth information about chemical structure, oxidation states, etc. Samples were filled into shallow wells of a custom-made sample holder and analysed at an emission angle of $0^{\circ}$ as measured from the surface normal. Assuming typical values for the electron attenuation length of relevant photoelectrons the XPS analysis depth (from which $95 \%$ of the detected signal originates) ranges between 5 and $10 \mathrm{~nm}$ for a flat surface. As 
the actual emission angle is ill-defined in the case of powders (ranging from $0^{\circ}$ to $90^{\circ}$ ), the sampling depth may range from $0 \mathrm{~nm}$ to approximately $10 \mathrm{~nm}$.

PEG and caspofungin grafting density on nanoparticles was determined by first measuring a layer thickness calculated from the attenuation of the underlying sulphur signal and the following equations adapted from Popat et al., 2004 and Zhu et al., 2001: 1-2

$$
\begin{aligned}
& \text { Layer Thickness }(T)=\text { Mean Free Path }(M F P) * \ln \left(\frac{\text { Initial Peak Intensity }}{\text { Final Peak Intensity }}\right) \\
& M F P=M F P @ 1 \mathrm{KeV} * \cos \theta * \text { Energy of Electron }^{0.79}
\end{aligned}
$$

A mean free path of $3.3 \mathrm{~nm} @ 1 \mathrm{KeV}$ was used for PEG and caspofungin. A weighted average layer thickness was calculated for multiple values of $\theta$ based on the work of Techane et al., 2011 to account for the spherical particle morphology. ${ }^{3}$ Using the calculated layer thickness a grafting density was estimated using the following equation:

$$
\text { Grafting Density (molecules } \left./ \mathrm{nm}^{2}\right)=\frac{\left.N_{A} \text { (molecules } / \mathrm{mol}\right) * \text { Density }\left(\mathrm{g} / \mathrm{cm}^{3}\right) * T(\mathrm{~nm})}{M W(\mathrm{~g} / \mathrm{mol}) * \operatorname{Conversion}\left(\mathrm{nm}^{3} / \mathrm{cm}^{3}\right)}
$$




\section{Supplementary Figures}
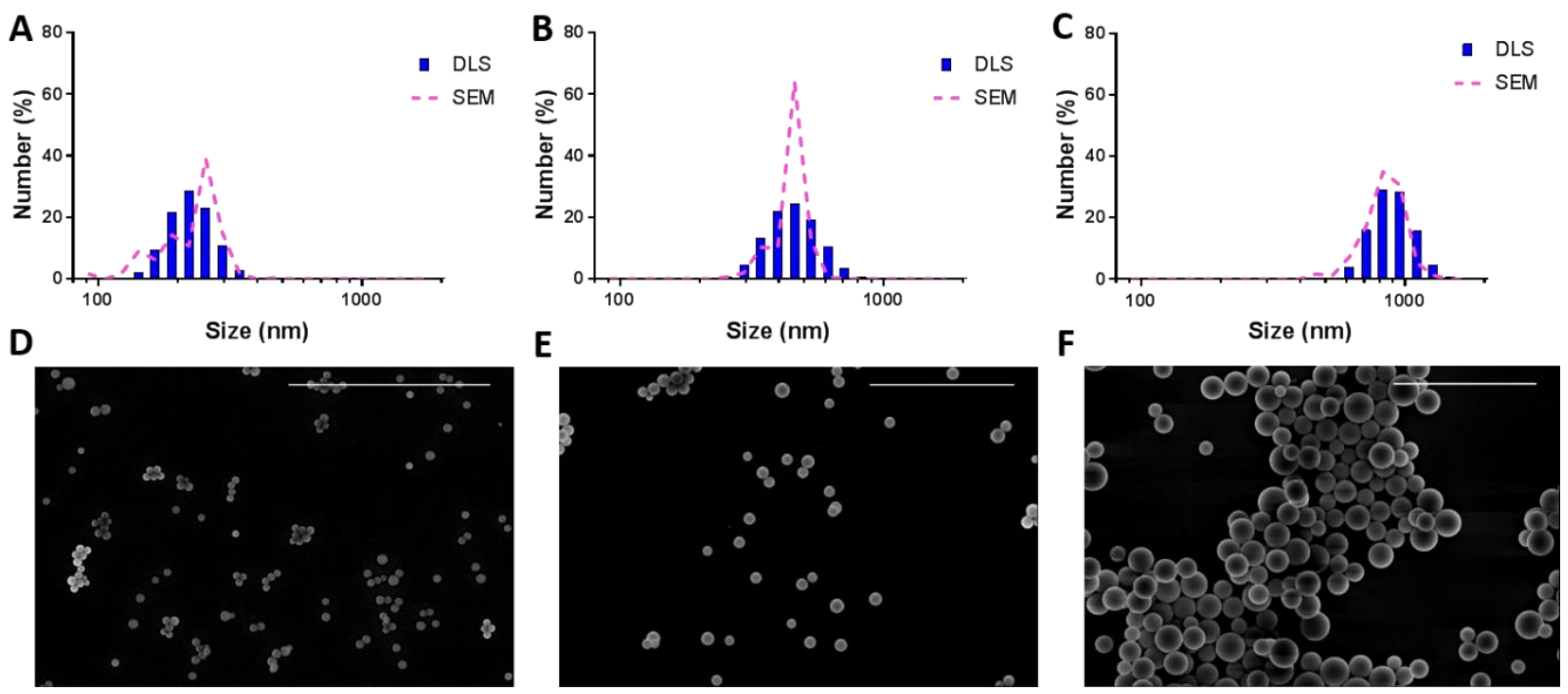

Figure S1. Size distribution of uncoated organosilica nanoparticles analysed by DLS and SEM. (A-C) show DLS and SEM size distributions of 200NP, 400NP and 800NP (uncoated). Corresponding SEM images (D-F) of 200NP, 400NP and 800NP nanoparticles reveal the spherical morphology of the organosilica nanoparticles. Scale bar represents $5 \mu \mathrm{m}$. 


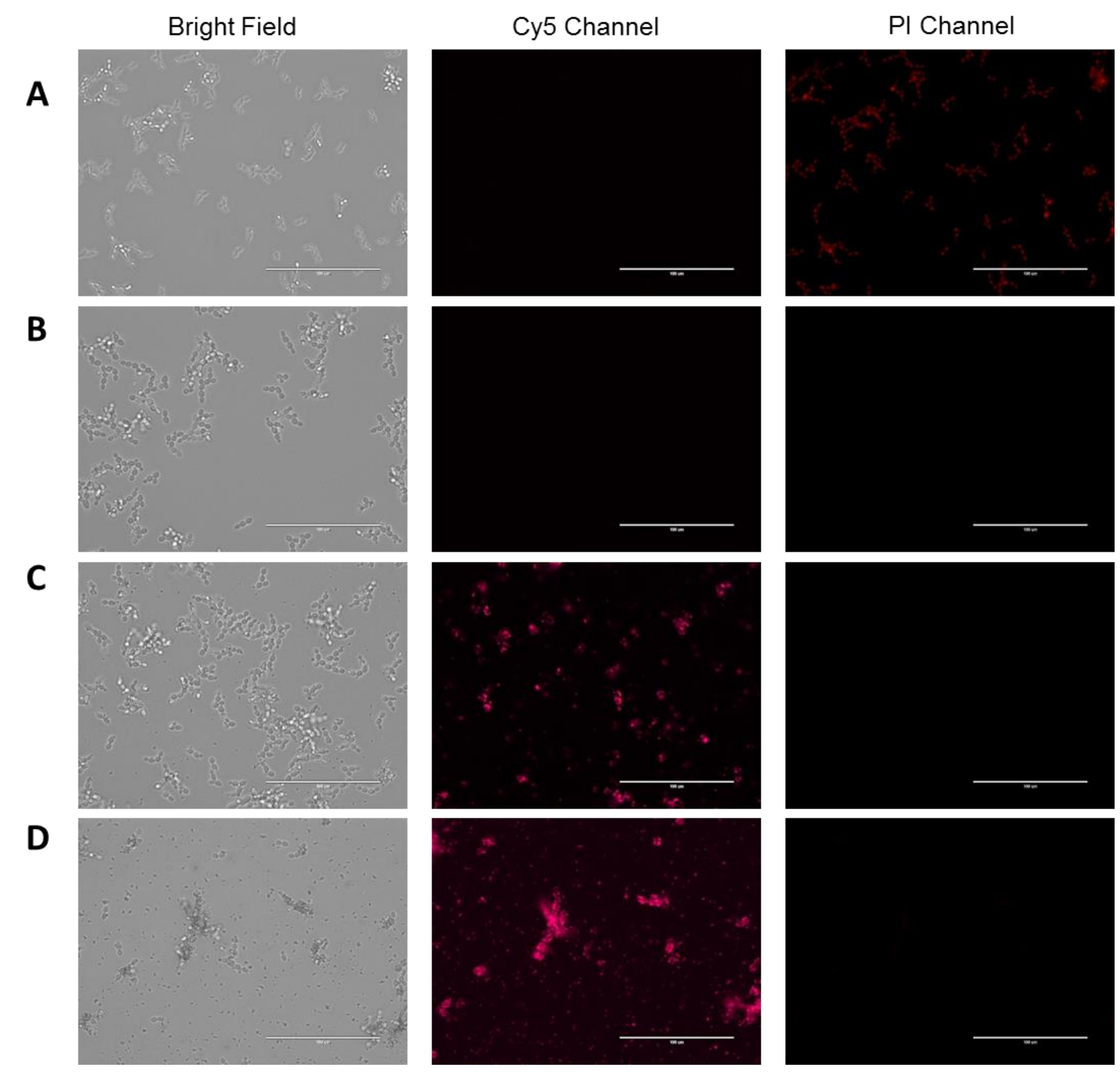

Figure S2. Viability of $C$. albicans yeast cells incubated with 800NP PEG coated nanoparticles for four hours at $30^{\circ} \mathrm{C}$. (A) Heat killed cells. (B) Untreated cells. (C) Cells incubated with $5.49 \times 10^{8} \mathrm{NP} \mathrm{mL}^{-1}$. (D) Cells incubated with $5.49 \times 10^{9} \mathrm{NP} \mathrm{mL}^{-1}$. The experiment was performed twice, using independent colonies of $C$. albicans and representative images have been shown. Scale bar represents $100 \mu \mathrm{m}$. 


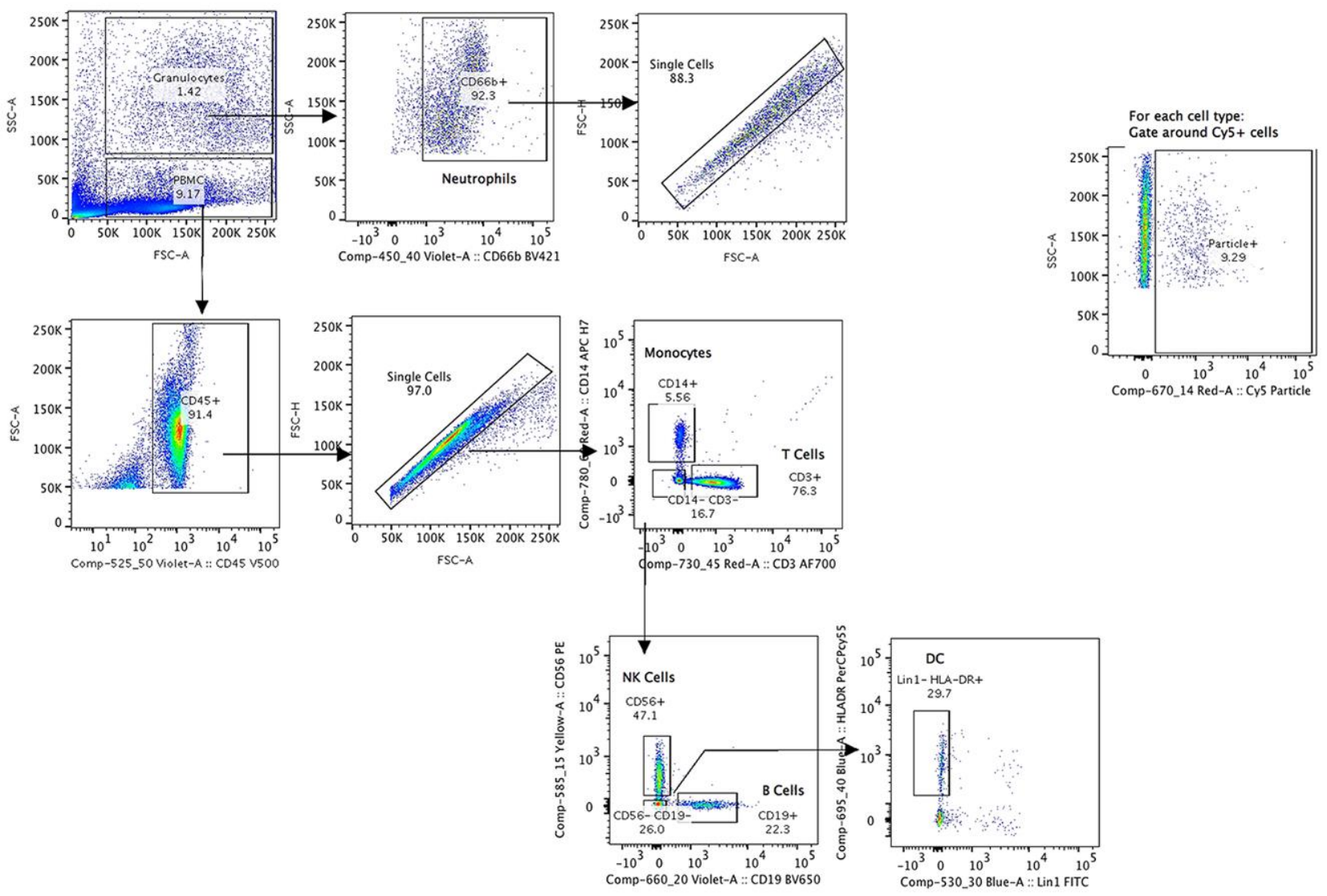

Figure S3. Representative gating strategy of blood assay from a single donor. Subpopulations of cells are identified as Granulocytes or Neutrophils, Monocytes, Natural killer (NK) cells, Dendritic cells (DC), B lymphocytes (B cells) and T lymphocytes (T cells). Nanoparticle-cell association with PEGylated nanoparticles is identified by looking at cells that appeared in the Cy5 gating.

Table S1. XPS analysis of uncoated, PEGylated and caspofungin-conjugated organosilica nanoparticles (data presented as relative atomic $\%$ with deviation between two samples).

\begin{tabular}{|c|c|c|c|c|c|c|c|c|}
\hline \multirow[b]{2}{*}{ Si } & \multicolumn{2}{|c|}{$\begin{array}{l}\text { Uncoated } \\
\text { organosilica }\end{array}$} & \multicolumn{2}{|c|}{$\begin{array}{l}\text { PEGylated } \\
\text { organosilica }\end{array}$} & \multicolumn{2}{|c|}{$\begin{array}{c}\text { PEGylated } \\
\text { organosilica + } \\
\text { caspofungin without } \\
\text { EDC/NHS }\end{array}$} & \multicolumn{2}{|c|}{$\begin{array}{c}\text { PEGylated } \\
\text { organosilica + } \\
\text { caspofungin with } \\
\text { EDC/NHS }\end{array}$} \\
\hline & 13.63 & 0.02 & 11.41 & 0.14 & 10.91 & 0.04 & 9.95 & 0.38 \\
\hline 0 & 23.06 & 0.10 & 25.51 & 0.22 & 24.65 & 0.11 & 24.54 & 0.30 \\
\hline $\mathbf{S}$ & 11.85 & 0.00 & 9.74 & 0.10 & 9.38 & 0.02 & 8.49 & 0.39 \\
\hline $\begin{array}{c}\text { C-C, C-H, C- } \\
\text { Si, C-S }\end{array}$ & 48.45 & 0.49 & 38.93 & 1.55 & 41.01 & 0.69 & 39.89 & 0.00 \\
\hline C-N, C-O & 2.46 & 0.00 & 12.94 & 1.13 & 10.93 & 0.62 & 13.04 & 1.00 \\
\hline $\begin{array}{c}\mathrm{C}=\mathrm{O}, \mathrm{O}-\mathrm{C}-\mathrm{O}, \\
\mathrm{N}-\mathrm{C}=\mathrm{O}\end{array}$ & 0.03 & 0.03 & 0.41 & 0.41 & 1.54 & 0.10 & 1.40 & 2.00 \\
\hline$O-C=0$ & 0.51 & 0.44 & 0.12 & 0.06 & 0.04 & 0.03 & 0.10 & 3.00 \\
\hline $\mathbf{N}$ & 0.00 & 0.00 & 0.94 & 0.08 & 1.52 & 0.02 & 2.51 & 0.40 \\
\hline
\end{tabular}




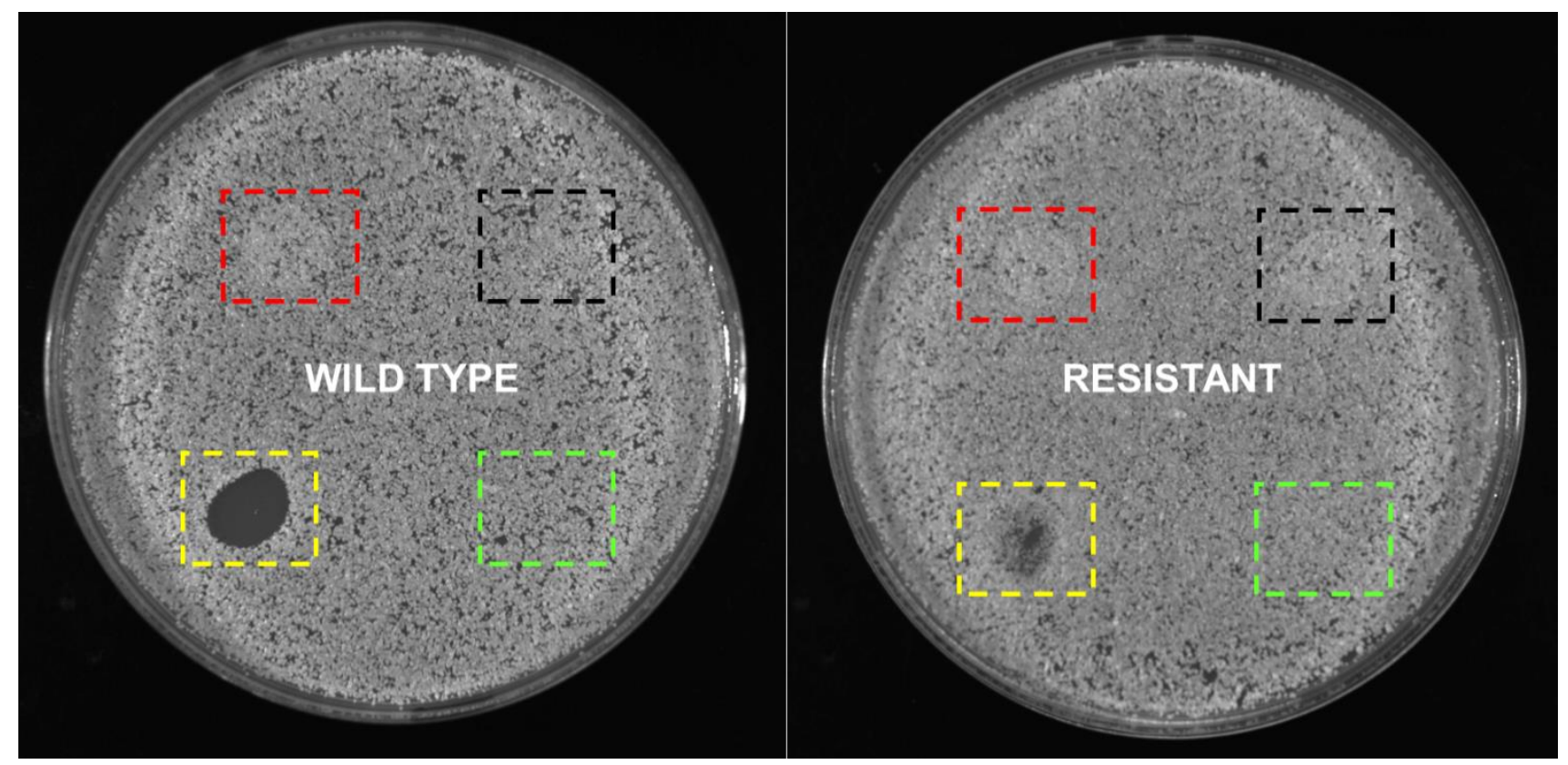

Figure S4. Caspofungin-conjugated particles did not inhibit $C$. albicans when dropped on plates at lower nanoparticle concentrations $\left(6.86 \times 10^{9} \mathrm{NP} \mathrm{mL}{ }^{-1}\right)$. Plates were seeded with a lawn of $C$. albicans $\left(\sim 1 \times 10^{6}\right.$ cells). The wild type strain, SC5314 (left), was used as the control, and compared to a genetically isogenic glucan synthase mutant, $\mathrm{RR}_{\mathrm{MHO}}$, which is resistant to caspofungin (right). 800NP PEG (highlighted in red), 800NP-Caspo (highlighted in black), $1 \mu \mathrm{gL}^{-1} \mathrm{caspofungin}^{-}$ in solution (highlighted in yellow), or supernatant obtained following 14-day incubation of caspofungin-conjugated nanoparticles (highlighted in green) were then added to the plate. Plates were incubated at $30^{\circ} \mathrm{C}$ for two days and photographed. The experiment was performed three times and representative images have been shown.

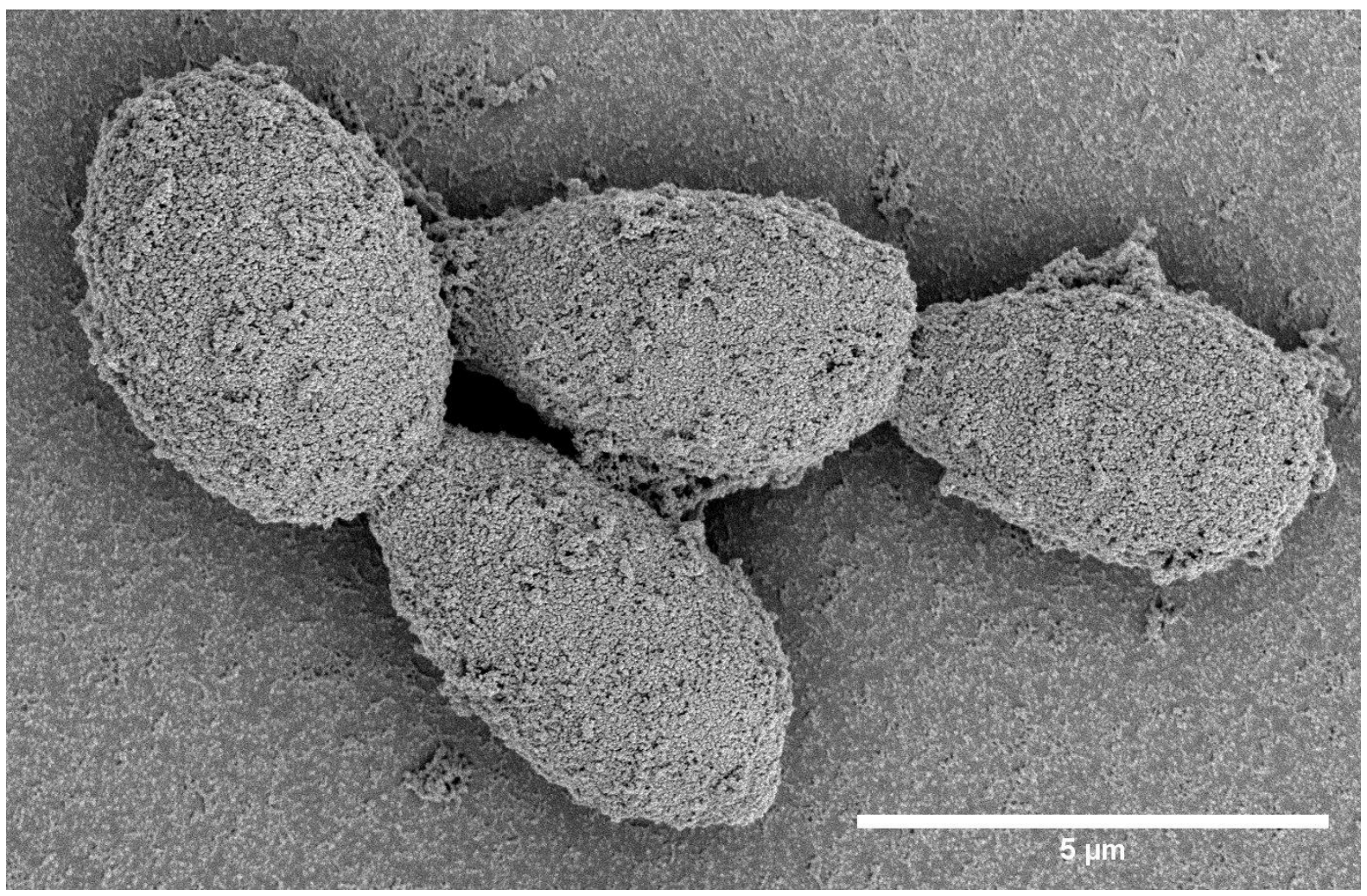

Figure S5. SEM image of $C$. albicans yeast cells (grown for four hours at $30^{\circ} \mathrm{C}$ in YPD in the absence of nanoparticles). Scale bar represents $5 \mu \mathrm{m}$. 


\section{References}

(1) Popat, K. C.; Sharma, S.; Desai, T. A. Quantitative XPS analysis of PEG-modified silicon surfaces. The Journal of Physical Chemistry B 2004, 108 (17), 5185-5188.

(2) Zhu, X.-Y.; Jun, Y.; Staarup, D.; Major, R.; Danielson, S.; Boiadjiev, V.; Gladfelter, W.; Bunker, B.; Guo, A. Grafting of high-density poly (ethylene glycol) monolayers on Si (111). Langmuir 2001, 17 (25), 7798-7803.

(3) Techane, S.; Baer, D. R.; Castner, D. G. Simulation and Modeling of Self-Assembled Monolayers of Carboxylic Acid Thiols on Flat and Nanoparticle Gold Surfaces. Analytical Chemistry 2011, 83 (17), 6704-6712, DOI: 10.1021/ac201175a. 